\title{
The patterning and functioning of protrusive activity during convergence and extension of the Xenopus organiser
}

\author{
RAY KELLER ${ }^{1}$, JOHN SHIH ${ }^{2}$ and CARMEN DOMINGO ${ }^{1}$ \\ 'Department of Molecular and Cell Biology, Universily of Califormia, Berkeley, Berkeley CA, USA \\ ${ }^{2}$ The Beckman Institute, California Institute of Technology, Pasadena CA, USA
}

\section{Summary}

We discuss the cellular basis and tissue interactions regulating convergence and extension of the vertebrate body axis in early embryogenesis of Xenopus. Convergence and extension occur in the dorsal mesoderm (prospective notochord and somite) and in the posterior nervous system (prospective hindbrain and spinal cord) by sequential cell intercalations. Several layers of cells intercalate to form a thinner, longer array (radial intercalation) and then cells intercalate in the mediolateral orientation to form a longer, narrower array (mediolateral intercalation). Fluorescence microscopy of labeled mesodermal cells in explants shows that protrusive activity is rapid and randomly directed until the midgastrula stage, when it slows and is restricted to the medial and lateral ends of the cells. This bipolar protrusive activity results in elongation, alignment and mediolateral intercalation of the cells. Mediolateral intercalation behavior (MIB) is expressed in an anterior-posterior and lateral-medial progression in the mesoderm. MIB is first expressed laterally in both somitic and notochordal mesoderm. From its lateral origins in each tissue, MIB progresses medially. If conver- gence does not bring the lateral boundaries of the tissues closer to the medial cells in the notochordal and somitic territories, these cells do not express MIB. Expression of tissue-specific markers follows and parallels the expression of MIB. These facts argue that MIB and some aspects of tissue differentiation are induced by signals emanating from the lateral boundaries of the tissue territories and that convergence must bring medial cells and boundaries closer together for these signals to be effective. Grafts of dorsal marginal zone epithelium to the ventral sides of other embryos, to ventral explants and to UV-ventralized embryos show that it has a role in organising convergence and extension, and dorsal tissue differentiation among deep mesodermal cells. Grafts of involuting marginal zone to animal cap tissue of the early gastrula shows that convergence and extension of the hindbrain-spinal cord are induced by planar signals from the involuting marginal zone.

Key words: convergence, extension, morphogenesis, motility, gastrulation, Xenopus.

\section{Introduction}

We have made significant progress in understanding the cellular basis of the powerful convergence and extension movements that function in gastrulation, neurulation and formation of the vertebrate body axis in amphibians (reviewed in Keller et al., 1991a, b; also see Keller et al., 1992a,b; Keller and Shih, 1992), as well as other vertebrates, including fish (Warga and Kimmel, 1990; Trinkaus et al., 1992) and birds (Schoenwolf and Alvarez, 1989). The cellular behavior underlying these movements in amphibians, their patterning and timing, and the geometry and mechanics of their function are very complex. For details, the reader should consult the papers cited above. We will use this occasion to provide a more accessible overview of the essential findings.

\section{Convergence and extension}

The terms 'convergence' and 'extension' were defined in the classical 'Entwicklungsmechanik' period of developmental biology and they describe the narrowing and lengthening of the dorsal tissues of the embryo, including the prospective notochord, somitic mesoderm and posterior neural plate during gastrulation and neurulation (see Keller et al., 199/b for a history) (Fig. 1A). These movements are important because they drive much of gastrulation (Keller, 1986) and constitute a major part of the morphogenetic activity of the Spemann organiser and of the nervous system that the organiser induces (Keller et al., 1991b; Keller et al., 1992a,b). These movements elongate the body axis, thus transforming the spherical egg into the elongate, bilaterally symmetrical vertebrate body plan. These movements are fundamental, general features of morphogenesis throughout the Metazoa, both during early and late stages of development and during regeneration (see Keller, 1987). Lastly, these movements are important because they represent the type of 'mass movement' in which mechanical integration of local cell motility produces forces that change the shape of the cell population, a process about which we know very 
little, despite its overwhelming contribution to the shaping of the embyro.

\section{Convergence and extension are studied in explants}

Although these movements have been described (Vogt, 1929; Keller, 1975, 1976; Jacobson and Gordon, 1976) and analyzed (Keller and Tibbetts, 1989; Keller et al., 1989a, b) in the whole embryo, the cell behaviors and mechanics underlying them can best be seen and analyzed in cultured explants. Convergence and extension of all dorsal tissues are displayed in sandwich explants of the dorsal marginal zone (DMZ) (Keller et al., 1985a, b; Keller and Danilchik, 1988) (Fig. 1B). There are two regions of convergence and extension, one in the involuting marginal zone (IMZ), consisting of prospective notochordal and somitic mesoderm and archenteron roof endoderm, and another in the prospective posterior neural plate, comprising the prospective hindbrain and spinal cord (Fig. 1B). Both show mechanically autonomous, active convergence and extension that are not dependent on cell traction on external substrata (Keller et al., 1985a, b). Thus the forces producing these movements must be generated within the explant.

\section{Convergence and extension occur by radial and mediolateral cell intercalation}

Convergence and extension in Xenopus occur primarily as a result of cell intercalations in two directions. These cell intercalations were revealed directly by time-lapse videorecordings of the deep cells in 'open-faced' explants, which expose these cells to observation (Wilson et al., 1989; Wilson and Keller, 1991; Keller et al., 1989a) (Fig. 1C). First, the deep cells intercalate perpendicular to the surface of the embryo such that several layers of deep cells form fewer layers of greater area (radial intercalation) (Fig. 2). For reasons not yet understood, the greater area produced by radial intercalation in the marginal zone is expressed solely by extension in the animal-vegetal (anterior-posterior) axis (Wilson and Keller, 1991), rather than in all directions, as is the case in epiboly of the animal cap (Keller, 1978, 1980). Following radial intercalation, the deep cells intercalate along the mediolateral axis to form a longer, narrower array (mediolateral intercalation), thus producing convergence and extension (Fig. 2). During this period of deep cell intercalation, the superficial epithelial cells spread, divide and intercalate mediolaterally to form a longer, narrower array, despite the fact that their apices are connected by a junctional complex (see Keller, 1978; Keller and Trinkaus, 1987).

This sequence of radial and mediolateral cell intercalations also produces convergence and extension of the posterior nervous system. By grafting patches of cells labeled with fluorescein dextran amine (FDA) into unlabeled hosts and monitoring their intercalation with unlabelled cells during subsequent stages of development, we showed that convergence and extension of the hindbrain and spinal cord in sandwich explants and in whole embryos also occurs by radial intercalation followed by mediolateral intercalation (Keller et al., 1992a,b). We also used this method to show that convergence and extension of the mesoderm occurs by radial (Keller et al, 1992a) and mediolateral intercalation (Keller et al., 1985a, b; Keller and Tibbetts, 1989) in whole embryos. Thus what is observed in the explants is not an artifact of manipulation or culture.

\section{The timing and position of radial and medlolateral intercalation}

Radial intercalation and mediolateral intercalation occur in sequence. Radial intercalation begins in the dorsal mesoderm at the early gastrula stage (stage 10) and is largely complete by the early midgastrula (stage 10.5). Then mediolateral intercalation begins, with some overlap, and continues until near the end of neurulation (stage 18). The same sequence occurs in the hindbrain-spinal cord, beginning slightly later than in the mesoderm. In both mesoderm (Wilson et al., 1989; Wilson and Keller, 1991; Shih and
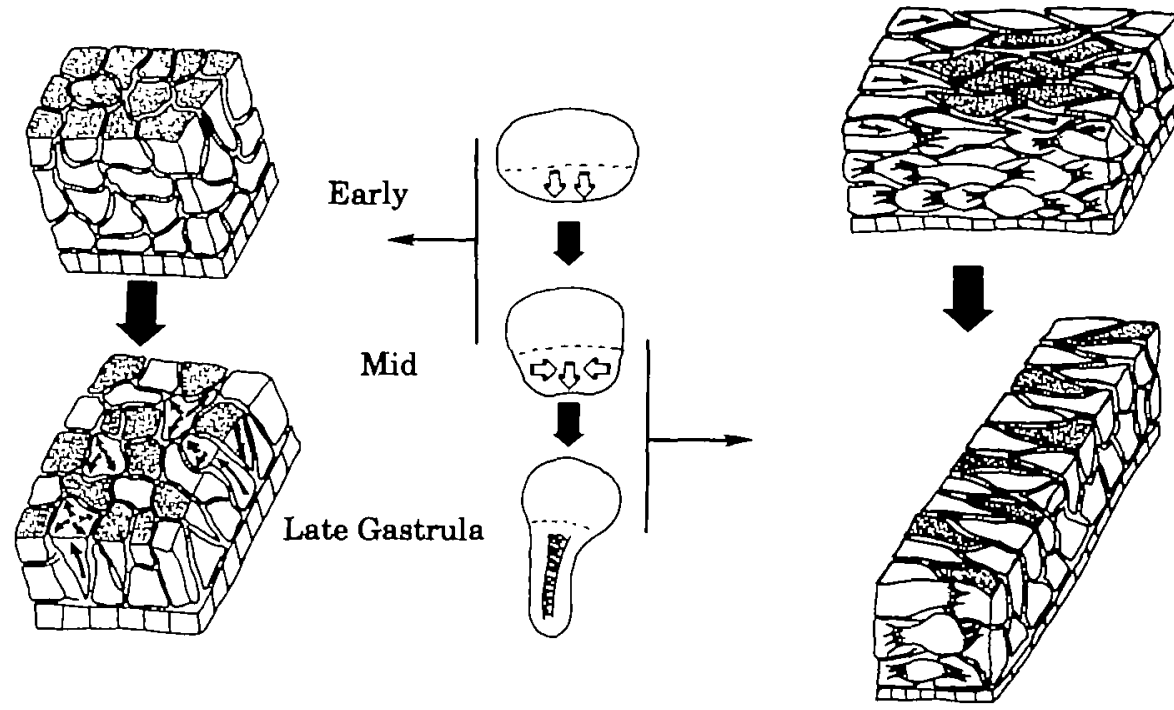

Radial Intercalation
Mediolateral Intercalation
Fig. 2. Diagrams show the cell intercalations underlying convergence and extension of the IMZ in open-faced explants. In the center column, change in the shape of open-faced explants are shown at early, middle and late gastrula stages and the cell behaviors producing these movements are shown on the sides. The inner, deepest surface is shown uppermost and the epithelial layer normally forming the outer surface of the embryo is at the bottom in all diagrams. The open arrows in the center column illustrate the tissue deformation. The small arrows on the cells in the right and left columns indicate the direction of cell movements. Radial intercalation (left) produces thinning and extension in the first half of gastrulation and mediolateral intercalation (right) produces convergence and extension in the second half. Modified from Wilson and Keller, 1991. 
$1 \mathrm{~A}$
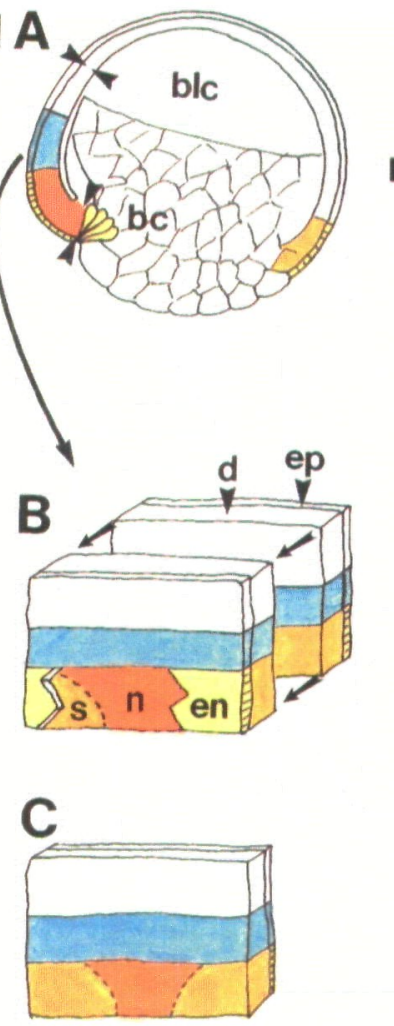

D

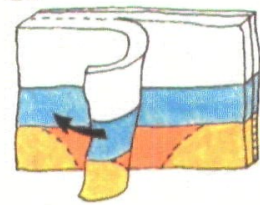

E

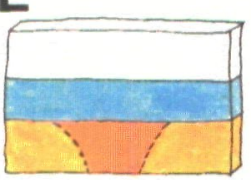

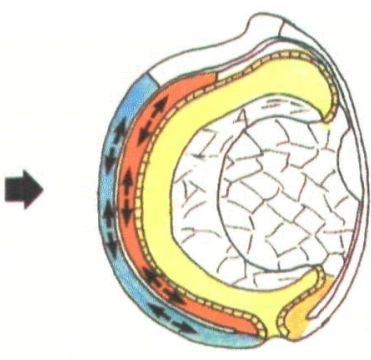
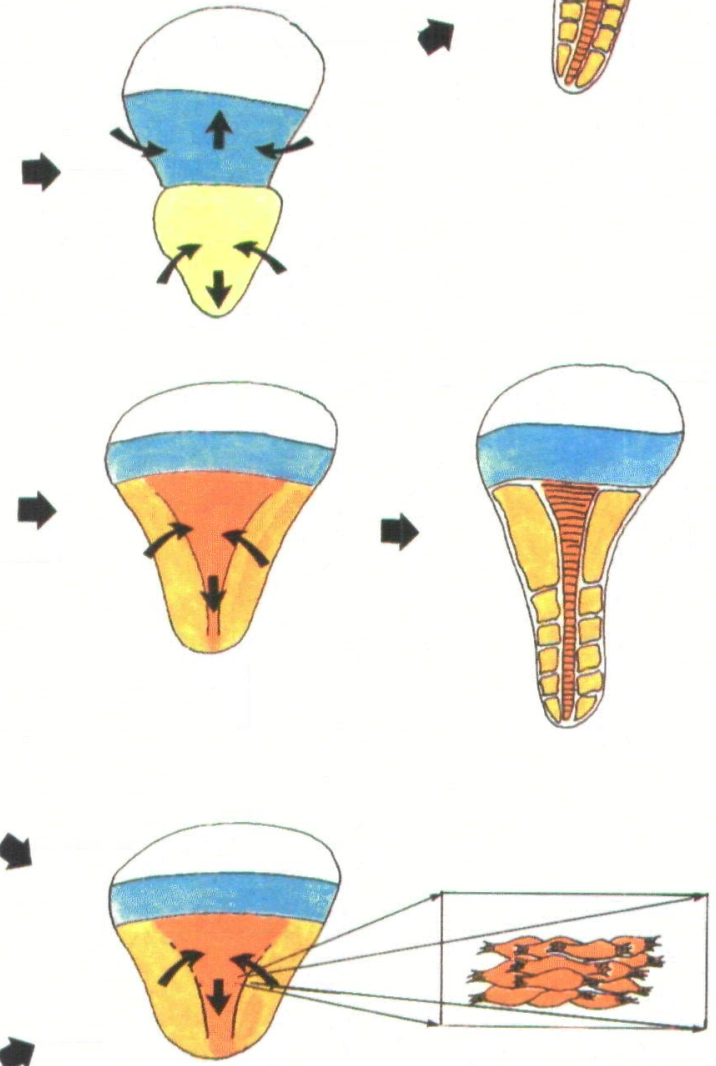

Fig. 1. Schematic diagrams show the convergence and extension of the involuting marginal zone (IMZ), shown in red (mesoderm) and yellow (endoderm), and the posterior neural plate (prospective hindbrain-spinal cord), shown in blue, in whole embryos (A) in sandwich explants (B), in openfaced explants $(C)$, in shaved. openfaced explants (D) and in deep cell explants (E). Arrows in the left column indicate manipulations of the tissue; arrows in the middle column indicate tissue movements. Sagittal views of the early gastrula and neurula show the extraordinary extension of the mesodermal and posterior neural tissues during gastrulation and neurulation $(A)$. Convergence and extension of both tissues occur in sandwich explants (B), made by cutting out the dorsal sector of the early gastrula and sandwiching it with another, identical explant. This explant consists of a superficial epithelium (ep) and a deep, nonepithelial (mesenchymal) region (d). It consists of an animal cap region (white), which normally forms forebrain, a nonınvoluting marginal zone (blue). which normally forms hindbrain and spinal cord. and an involuting marginal zone, consisting of a superficial layer of prospective endoderm (en, yellow), and a deep region of prospective notochordal ( $\mathrm{n}$. red) and somitic (s. orange) mesoderm. Open-faced explants (C) are designed to expose the deep mesodermal cells to observation and consist of one explant cultured in modified Danilchik's solutıon under a coverslip conditions under which the IMZ will converge. extend and differentiate into somites and notochord. Shaved open-faced explants are a further modification designed to expose the deep cells next to the overlying endodermal epithelium (D). These are made and cultured like openfaced explants but the innermost layers of deep cells are shaved or peeled off with an eyebrow knife, exposing the deep cells next to the endodermal epithelium to observation and videorecording for analysis of cell behavior at high resolution (box, D). Lastly, deep cell explants are made from stage 10.5 or 11 embryos in which the same tissues are excised and the adjacent sheet of prospective endoderm removed, leaving a layer of deep mesodermal cells. (E). Convergence and extension of the deep mesoderm is largely independent of the overlying epithelium after these stages. The mesoderm is partially involuted at these stages and must be straightened before culture (not shown). Modified from Keller et al., 1991a. 
$3 \mathrm{~A}$

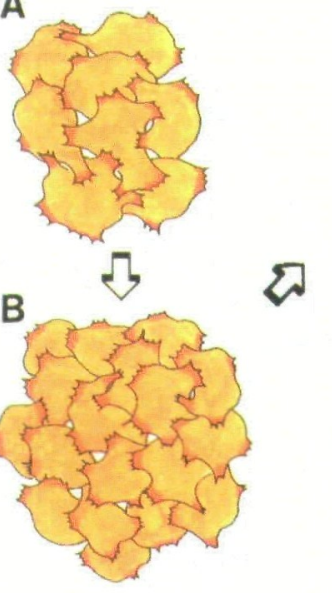

C
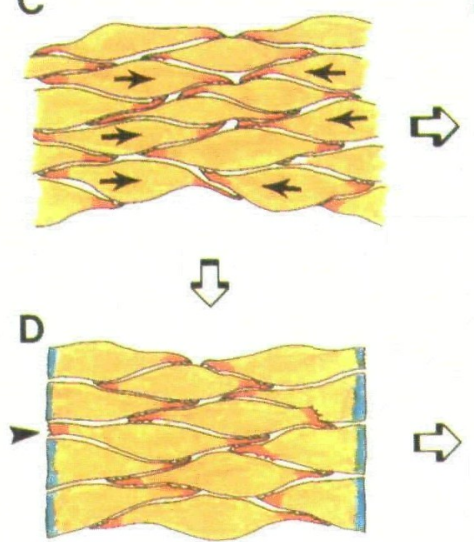

E

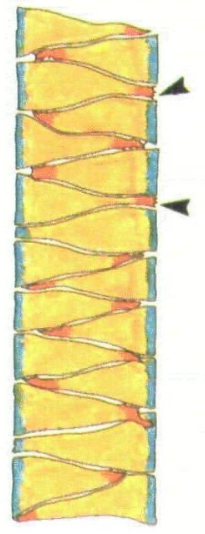

Fig. 3. The cellular behavior and protrusive activity driving mediolateral intercalation of deep mesodermal cells are illustrated. In the early gastrula (stage 10-10.5) the deep mesodermal cells divide once and show rapid protrusive activity (red) oriented in all directions (A,B). At the midgastrula stage (10.5), cell division ceases. protrusive activity slows dramatically and protrusive activity becomes polarized in the form of large, stable protrusions at the medial and lateral ends of the cells (C). These directed, stable protrusions are applied direcily to the surfaces of adjacent cells and advance between adjacent cells without contact inhibition. Traction generated in the mediolateral axıs by these oriented, invasive protrusions result in mediolateral cell elongation. alignment and intercalation (C). Mediolateral intercalation results in the convergence and extension of the cell population through the rest of gastrulation and neurulation (C-E). Al stage 11 and thereafter, the boundary between notochordal and somitic mesoderm forms and inhibits the invasive, protrusive activity where the bipolar cells contact the boundary (blue), making the boundary cells monopolar in protrusive activity Thus internal cells are captured at the boundary and elongate the boundary while pulling more deep cells to the boundary (D.E) (see Keller et al.. 1989:1) Active protrusions entering the boundary (ponters. D. E) first bleb. spread on the boundary and then cease all protrusive activity. 
Keller, 1992a) and in the neural tissue (Keller et al., 1992a), intercalation begins in the prospective anterior end and proceeds posteriorly. Mediolateral intercalation begins in the post-involution, prospective anterior axial mesoderm and proceeds posteriorly, forming a constriction ring at the blastoporal lip that drives involution of the marginal zone (Keller, 1986; Wilson and Keller, 1991). These observations explain how convergence and extension of the IMZ can drive much of gastrulation without participation of other components of the gastrula (Keller et al., 1985a, b). If the continuity of the constriction ring is broken, involution fails and 'ring' embryos form (Schechtman, 1942; Keller, 1984).

\section{Bipolar, mediolaterally directed protrusive activity drives mediolateral cell intercalation, and convergence and extension}

We were unable to see how cells generate the forces that move them between one another by videorecording the deep cells at the inner surface of the open-faced explant (Fig. IC). The deepest mesodermal celis do not participate in active mediolateral cell intercalation until later stages (see Keller et al., 1989a; Wilson et al., 1989), because the overlying endodermal epithelium organises mediolateral intercalation from the outside inward (see discussion below and Shih and Keller, 1992a). Thus, to observe the deep cells immediately beneath the epithelium, we developed the 'shaved' explant in which the deepest mesodermal cells in the open-faced explant are shaved off with an eyebrow hair, exposing the ones immediately beneath the epithelium to observation, videorecording and manipulation (Fig. ID). Alternatively, we made explants of only the deep mesoderm of the early midgastrula (stage 10.5 ), which by this time has been thinned by radial intercalation and is no longer dependent on the overlying epithelium to organise mediolateral intercalation. This explant consists of only deep mesodermal cells and most or all the cells can be seen, thus negating the problem that unseen cells may be generating forces that we attribute to the cells that we observe.

The cell behavior in these two types of explants was recorded with epi-illumination and protrusive activity was recorded with low-light, fluorescence microscopy and image processing (Keller et al., 1989a; Keller et al., 199la, b; Shih and Keller, 1992b). We will summarize our understanding of the mechanism of deep mesodermal cell intercalation (Fig. 3) and then show examples of evidence supporting these ideas.

Deep mesodermal cells divide once in early gastrulation, while remaining isodiametric and showing rapid, randomly directed protrusive activity (Fig. 3A, B). Then, at the transition of early and midgastrulation (stage 10.5) (Fig. 3C), protrusive activity slows dramatically and becomes directed medially and laterally in the form of large lamelliform and filiform protrusions applied to the surfaces of adjacent cells. The cells elongate, align and intercalate parallel to the mediolateral axis and perpendicular to the anterior-posterior axis (animal-vegetal axis) (Fig. 3C). They then intercalate mediolaterally to form a longer narrower array (Fig. 3C, E).

These events appear directly related to the traction of the large medial and lateral protrusions on adjacent cells. These protrusions advance across the neighboring cells without contact inhibition of movement. When the notochordsomitic mesodermal boundary forms, beginning at stage 11, the bipolar cells in the region of the boundary cease protrusive activity at their boundary-facing margin (Fig. 3D) (Keller et al., 1989a). Protrusions of cells entering the boundary by intercalation (pointers, Fig. 3D,E), first bleb violently, then spread in the plane of the notochord boundary and finally cease all protrusive activity. Thus, they become monopolar and stabilize their position at the boundary while they exert traction on deeper cells (Fig. 3D) (Keller et al., 1989a; Shih and Keller, 1992a). As a result, internal cells are pulled to the boundary and captured there, thus elongating the boundary (Fig. 3D,E). Both the bipolar and monopolar protrusive activity contributes to mediolat-
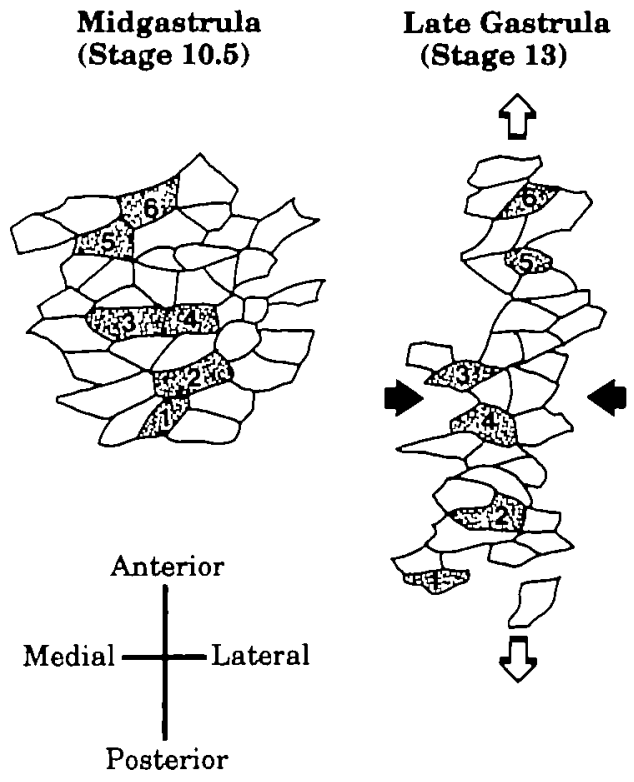

Fig. 4. Cell tracings from a deep cell explant show mediolateral intercalation of deep mesodermal cells during convergence and extension of an explant without the endodermal epithelium. The filled arrows indicate convergence movements and the open arrows indicate extension movements. 

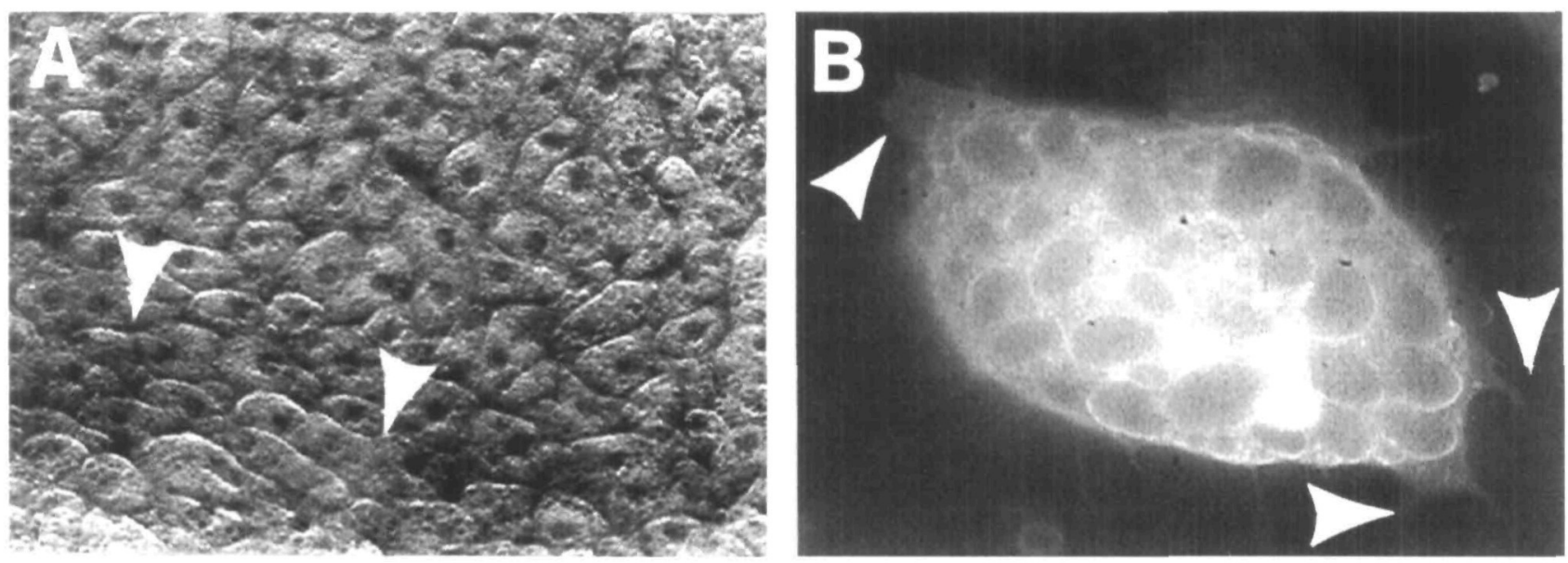

Fig. 5. A print of a videorecording made with epi-illuminatıon shows the mediolateral cell elongation and alignment accompanying mediolateral cell intercalation (below pointers, A). A print of a videorecording made with low-light fluorecence microscopy and image processing of Dil-labeled, intercalating mesodermal cell shows the bipolar morphology, mediolateral elongation (upper left to lower right) and protrusive activity at the medial and lateral ends (pointers, B). Another Dil-labeled cell lies beneath the lower edge of the brightly labeled cell.

eral cell intercalation. The bipolar, medially and laterally directed protrusive activity exerts traction on adjacent cells, elongates them, aligns them and pulls them between one another to form a longer, narrower array prior to notochordal-somitic boundary formation (Fig. 3C-E). This process continues in central regions after the boundary forms, bringing more cells within reach of the boundary, where the monopolar activity and cell capture elongates the boundary.

Tracking of individual cells in time-lapse recordings shows details of cell shape changes and mediolateral intercalations during convergence and extension (Fig. 4). Although cells elongate mediolaterally and shorten anteriorposteriorly, their mediolateral intercalation is sufficient to produce convergence and extension of the tissue (see shaded cells, Fig. 4). The pattern of intercalation is indeterminate, with no precise order of intercalation (Fig. 4). Cells will occasionally change anterior-posterior or medio-
Stage $10-10.25$

A

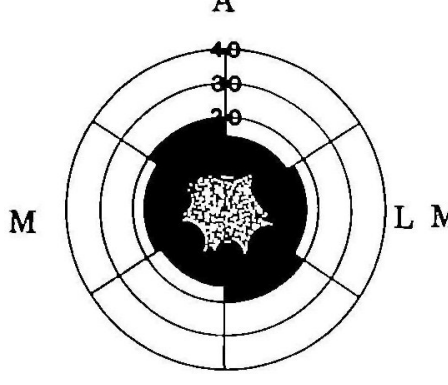

$P$
Stage 10.5-12

A

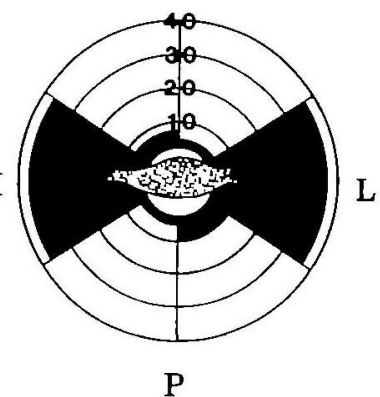

$\mathrm{P}$
Fig. 6. Plots of percent of protrusive actıvity in each of 6 sectors around the deep mesodermal cells shows the initial random orientation in the early gastrula (left) and the dramatic restriction of protrusive activity to the lateral and medial ends of the cells after the midgastrula stage when these cells are intercalating mediolaterally (right). lateral positions once or even several limes in the course of intercalation. Little or no cell division occurs during mediolateral intercalation. Epi-illumination shows the dramatic mediolateral elongation and alignment that accompanies mediolateral intercalation (Fig. 5A). Low-light, fluorescence microscopy and video image processing shows that bipolar protrusive activity, directed medially and laterally, drives the elongation, alignment and intercalation of mesodermal celts (Fig. 5B). Plots of the direction of protrusive activity from recordings of fluorescently labeled cells show protrusive activity is randomly directed in early gastrulation (stage 10-10.25) and is polarized medially and laterally in the second half of gastrulation (stage 10.5-12), when the cells elongate, align and intercalate (Fig. 6). (For details and additional evidence see Keller et al., 1989a, b). Also, computer modelling of rules of cell behavior has proven useful in evaluating the contribution of specific cell behaviors to the cell intercalation, cell shape changes, and convergence and extension of the notochord (Welicky et al., 1991).

\section{Patterns of mediolateral intercalation behavior (MIB)}

The bipolar protrusive activity, cell elongation and cell alignment that precede and accompany mediolateral intercalation are collectively called mediolateral intercalation behavior (MIB) and the expression of MIB can be followed in large explants by following cell elongation and alignment. MIB is expressed progressively across the mesodermal cell population in a pattern that reflects both the function of mediolateral intercalation in gastrulation and the progress of the signalling and response system that organises the IMZ (Shih and Keller, 1992a). The progression of MIB will be described in terms of the anterior-posterior and lateromedial axes of the prospective notochord and somitic mesoderm in large explants of the IMZ (Fig. 7), and MIB 


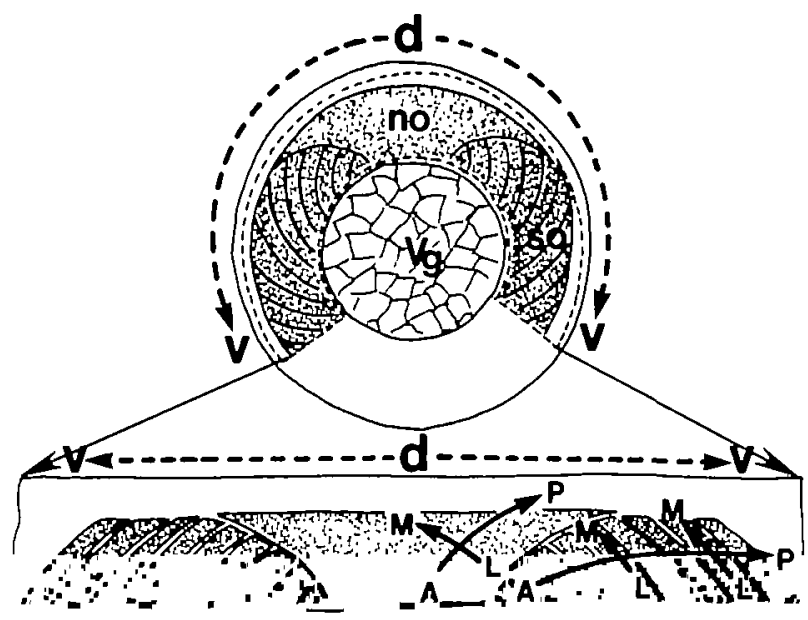

Fig. 7. The top diagram shows the vegetal $(\mathrm{Vg})$ aspect of the early gastrula as it would appear if the dorsal 270 degrees of superficial endoderm were removed, exposing the prospective mesodermal tissues, including the notochord (no) and somitic (so) mesoderm. Patterning of mediolateral intercalation behavior (MIB) was studied in large explants of this mesoderm, shown in the bottom diagram. The patterning of MIB will be discussed in the context of the prospective anterior $(\mathrm{A})$ to posterior $(\mathrm{P})$ and lateral $(\mathrm{L})$ to medial $(\mathrm{M})$ axes of the prospective notochordal and somitic mesoderm in these large explants of the marginal zone. The dorsal (d) to ventral (v) axis of the gastrula is indicated by a dashed line. This diagram is based on Keller, 1975, 1976; Wilson et al., 1989 and Keller et al., 1989.

will be represented as elongated and aligned cell outlines (Fig. 8). MIB produces convergence and extension, but in turn convergence and extension modifiy the expression of MIB. Therefore, we will compare MIB expression in explants in which convergence and extension has been blocked by mechanical resistance (Fig. 8A) with explants that converge and extend (Fig. 8B).

MIB is expressed first in an arc at the anterior end of the axial mesoderm, called the vegetal alignment zone ( $\mathrm{VgAZ}$ ). The $\mathrm{VgAZ}$ is initiated bilaterally, about 15 degrees from the midline and progresses towards the midline in the early midgastrula (Fig. 8, stage 10.5-10.75). MIB then spreads laterally and ventrally along the vegetal edge of the IMZ (Fig. 8, stage 11), which is an anterior-posterior progression along the lateral edge of the prospective somitic mesoderm (refer to Fig. 7). The boundary of the notochord forms at the midgastrula stage (stage 11), beginning within the $\mathrm{VgAZ}$ and progressing posteriorly (Fig. 8, stage 11onward). MIB then spreads posteriorly from its origin in the $\mathrm{VgAZ}$, following the lateral aspect of the notochord, along its boundary (Fig. 8, stage 11-onward). From its origin laterally in the somitic mesoderm, MIB progresses medially, toward the prospective notochord. From its lateral origin in the notochord, it spreads medially towards the center of the notochord territory (Fig. 8, stage 11-onward). Differentiation of the notochord, as indicated by vacuolation and by staining with notochord-specific antibody tor70 (Domingo, unpublished results), and differentiation of somitic mesoderm, as indicated by segmentation and staining with somite-specific antibody 12-101, follow the pattern of MIB expression, beginning anteriorly, progressing posteriorly along the lateral boundaries and progressing medially from the lateral boundary at any anterior-posterior level.

The expression of MIB and differentiation of cells in the posterior-medial region of both the notochordal and somitic territories is dependent on convergence bringing these cells closer to the lateral boundaries. If the explant encounters too much mechanical resistence, the bipolar protrusive activity results in elongation and alignment of the cells but they do not intercalate and thus convergence and extension do not occur. In this case, those cells farthest from the boundaries in the medial, posterior regions, do not show MIB or differentiate (black dots, Fig. 8A, stage 11 -onward). If convergence and extension are allowed to occur, cell elongation and alignment are followed by mediolateral intercalation and convergence and extension, bringing the lateral boundaries of the notochord and somitic mesodermal territories closer to their respective medial cells (Fig. $8 \mathrm{~B})$. In this case, the medial cells express MIB and differentiate.
A

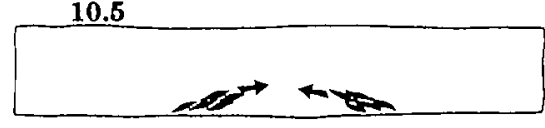

10.75

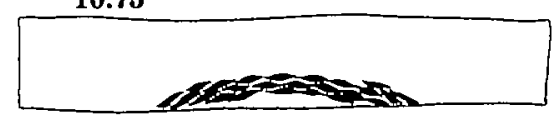

11
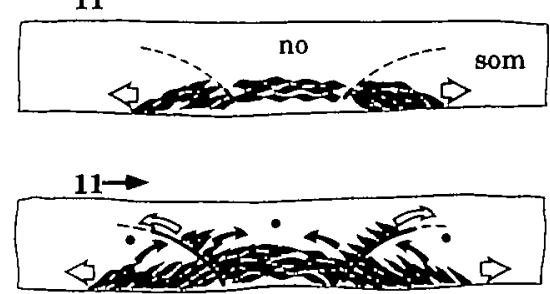

B

10.5

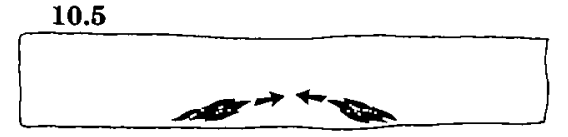

10.75

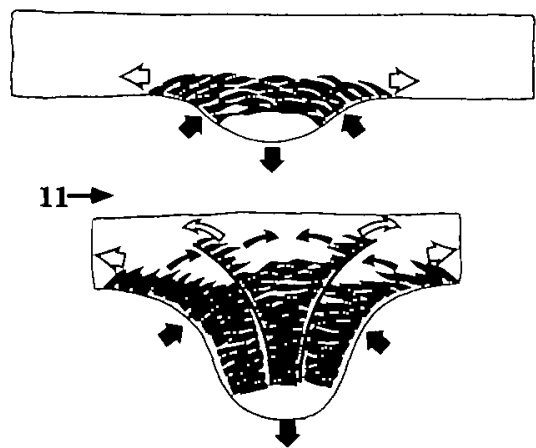

Fig. 8. Patterns of progression of mediolateral intercalation behavior (MIB) are represented by outlines of elongated, aligned cells in explants not allowed to converge and extend $(A)$ and ones that are allowed to converge and extend $(B)$. The numbers above each explant indicate stage of development. The solid arrows inside the explants indicate lateral-medial progression of MIB and the open arrows indicate anterior-posterior progression. The arrows outside the explants show the direction of convergence and extension, when they occur. Prospective notochord (no) and somitic mesoderm (som) and the prospective boundary between them (dashed line) are indicated. Formation of the boundary is indicated by a heavy line. The black dots indicate areas that do not express MIB or differentiate in nonextending, nonconverging explants. 


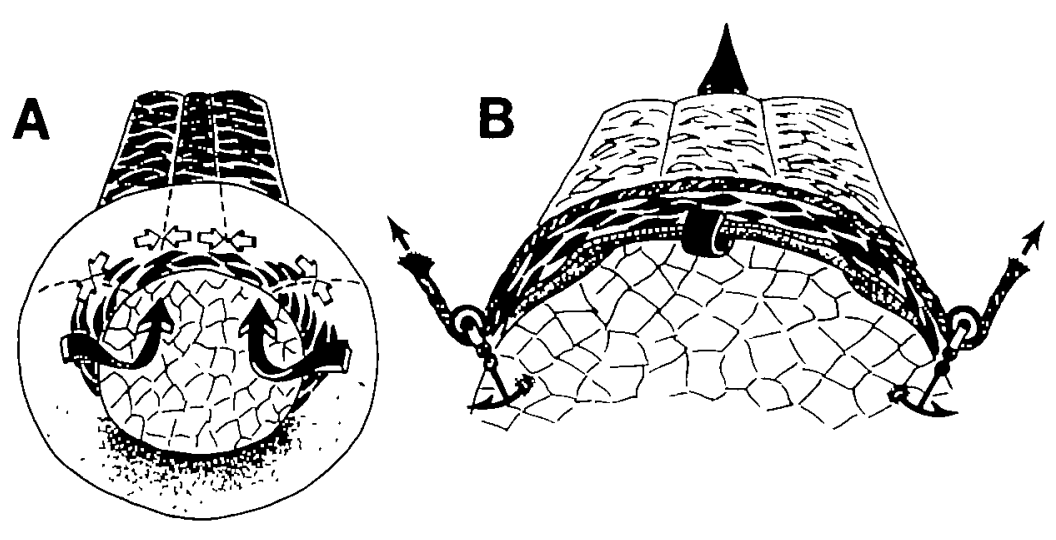

Fig. 9. Posterior progression of mediolateral intercalation in the involuted mesoderm approaches the blastoporal lip (black cell outlines) and forms a constricting arc at the blastoporal lip (open arrows, A). The constricting arc is anchored in the vegetal endoderm at each end and, as it constricts, it functions to roll the pre-involution IMZ over the lip, as indicated by the rope and pulley analogy (B).

\section{Mechanical function of MIB progression in gastrulation}

The anterior-posterior progression of MIB has a specific mechanical function in gastrulation. At the beginning of gastrulation, the leading edge of the IMZ involutes as a result of active mesodermal cell migration (Winklbauer, 1990) and bottle cell formation (Hardin and Keller, 1988). Once involution is initiated, MIB expression begins in the anterior region of the $I M Z$ just inside the blastoporal lip and progresses posteriorly to the blastoporal lip (Fig. 9A). At the blastoporal lip, MIB and the resulting intercalation forms a constriction ring, anchored laterally in the vegetal endoderm. that presses on the inner surface of the blastoporal lip (Fig. 9B). As this constriction ring progresses posteriorly in the IMZ, it pulls the remaining IMZ over the lıp (Fig. 9B). The function of these arcs during involution is illustrated dramatically by the fact that breaking their continuity in the dorsolateral sector results in the extension of the dorsal sector (notochord) straight out into the medium and the development of somites in situ, without involution, around the margins of the vegetal endoderm (see Keller, 1981, 1984; Schechtman, 1942). Moreover, the constriction forces generated by this posteriorly progressing arc of intercalating cells can produce involution of the remaining IMZ without the participation of forces generated by animal cap epiboly, mesodermal cell migration, or neural extension and convergence. These regions can be removed, yet involution of the notochordal and somitic mesoderm goes on unabated (Keller et al., 1985a. b; R. Keller and S. Jansa, unpublished results).

\section{Significance of MIB progression for patterning}

Although the anterior-posterior progression of cell behavior and differentiation could be predicted from previous work (see Wilson et al., 1989; Wilson and Keller, 1991), it was unexpected that cell behavior in axial and paraxial mesoderm would progress medially from lateral boundaries. Several facts suggest that the progression reflects the order in which the cells received the signals eliciting these cell behaviors. The simplest explanation of the MIB progression itself is that the cells receive the signals organising MIB in the order of MIB expression. The fact that cells not allowed to approach the boundaries, from which MIB and differentiation begin, do not show expression of MIB or differentiation implies that these boundaries provide the organising signals. Finally, a linear array of early gastrula animal cap cells grafted into the central notochordal terri- tory, express MIB and differentiate from the anterior end posteriorly (C. Domingo, unpublished results). This means that these cells must be receiving organising signals from the notochord field in the order of MIB expression, since these cells do not normally express MIB at all, much less in a progressive pattem. We are currently testing for lateral-medial progression of behavior among strings of animal cap cells grafted into the $I M Z$ in this orientation. Progressive reception of organising signals predicts that commitment of cells to behavioral and histological phenotypes should also be progressive from lateral to medial and anterior to posterior. We are testing this by moving cells from notochordal to somitic territories (and vice versa) and from medial to lateral positions (and vice versa) within each tissue. It is not clear at this point whether the progression of MIB reflects a propagation of a mechanical component of specification or a propagation of a specifying signal per se.

These results suggest a revision of our ideas about the geometry of the signals patterning notochordal and somitic mesoderm. Grafts of dorsal marginal zone or 'organiser' to the ventral marginal zone induce ventral tissues to make dorsal mesodernal and neural tissues (Spemann, 1938; Gimlich and Cooke, 1983). Explants of ventral marginal zone will not make dorsal tissues in isolation (Dale and Slack, 1987), nor will these tissues converge and extend (Keller and Danilchik, 1988). These facts suggest that a dorsalizing signal emanates from the organiser and passes laterally and ventrally in the marginal zone, converting these tissues to dorsal fates (the third signal in the the threesignal hypothesis; see Dale and Slack, 1987). The term 'dorsalizing' is correct in that the dorsalizing signal converts what would have become belly mesodermal derivatives (mesothelium and blood) to somitic tissue. But it is somewhat misleading, since the result of this signal is primarily the addition of prospective posterior somites to the segmental plate and thus it acts along the prospective anterior-posterior axis rather than along the dorsal-ventral axis of the notochordal and somitic mesoderm (Fig. 7). The actual mediolateral patterning or dorsal-ventral patterning within the prospective notochordal-somitic mesoderm is determined in a lateral-to-medial order, along arcs emanating from the vegetal edge of the $\mathrm{IMZ}$ and arcing toward the midline, parallelling the progress of the MIB expression The first sign of dorsal behavior is MIB expression at the lateral edge of the somitic territories, which then arcs to the 
midline. The next patterning event is establishment of the notochordal-somitic boundary transverse to this arc. Finally, cell behavior and differentiation occur from lateral boundaries towards the medial region within both these territories.

The anterior-posterior and lateral-medial progressions could be explained with a predominately anterior-posterior signal radiating from the mid-dorsal region, somewhere in the vegetal endoderm, and passing along the anterior-posterior axes of notochordal and somitic mesoderm (Fig. 7). This signal would intersect with signals that had already set up special competences in the territories destined to be lateral somitic mesoderm and lateral notochordal mesoderm, such that cells in these regions would then organize their own type of behavior and differentiation medially from the boundary. Responses of cells to combinations of growth factors have led to the idea that mesodermal phenotypes may be determined by threshold responses to intersecting concentration gradients of two signals. Response thresholds would thus be expected to give rise to sharp boundaries, such as the notochord-somite boundary discussed (Green, 1992).

It should be noted that the medial edges of only the first 6 or 7 somites meet the notochord. More posterior somites come to lie next to the notochord as the notochord extends in the late gastrula and neurula. The notochord shears posteriorly with respect to the somitic mesoderm and pushs the
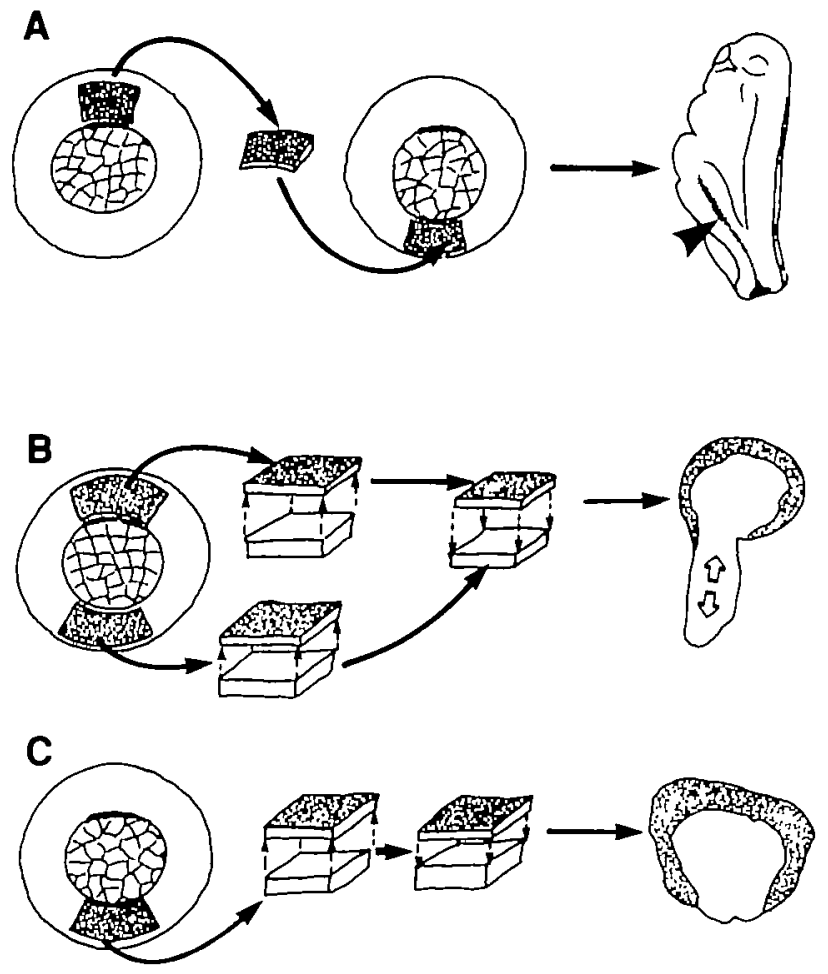

Fig. 10. Grafts of dorsal epithelium of the early gastrula to the ventral side of another early gastrula result in formation of a secondary axis (pointers) on the ventral side of the host embryo (A). Recombinant explants of dorsal epithelium and ventral deep cells converge, extend (open arrows) and differentiate dorsal tissues $(B)$ whereas if the same tissues of the ventral marginal zone are separated and recombined, no convergence and extension or dorsal tissues develop (C). Modified from Keller et al., $199 \mathrm{lb}$. blastopore posteriorly. As this occurs, the somitic mesoderm lying lateral and ventral to the blastopore swings dorsally alongside the notochord (Wilson et al., 1989; Keller et al., 1989a). These movements, rather than the earlier convergence movements (Fig. $8 \mathrm{~B}$ ), bring the ventral tissues of prospective posterior somitic mesoderm dorsally, next to the notochord (see Figs 5 and 6, Keller et al., 199lb).

\section{Epithellal mesenchymal interactions controlling mesodermal cell intercalation}

The endodermal epithelium of the marginal zone is essential for the deep mesodermal cells to develop the ability to undergo mediolateral intercalation independently. If the endodermal epithelium is removed from explants in the early gastrula stage, convergence and extension do not occur (Wilson, 1990). After the early gastrula stage (stage 10.5), the deep cells are capable of independent convergence and extension by mediolateral cell intercalation without the epithelium (Fig. 4). The epithelial layer is not necessary for production of mechanical forces since deep cells alone can converge and extend after the early gastrula stage. The epithelial layer appears to provide the deep cells with essential support or instruction on how to do mediolateral cell intercalation. Grafts of the dorsal epithelial layer of the early gastrula to the ventral marginal zone of normal animals result in the formation of a second set of posterior axial structures, including notochord, somitic mesoderm and neural tissue (Fig. 10A) (Shih and Keller, 1992c). Also, embryos ventralized with UV irradiation can be rescued to

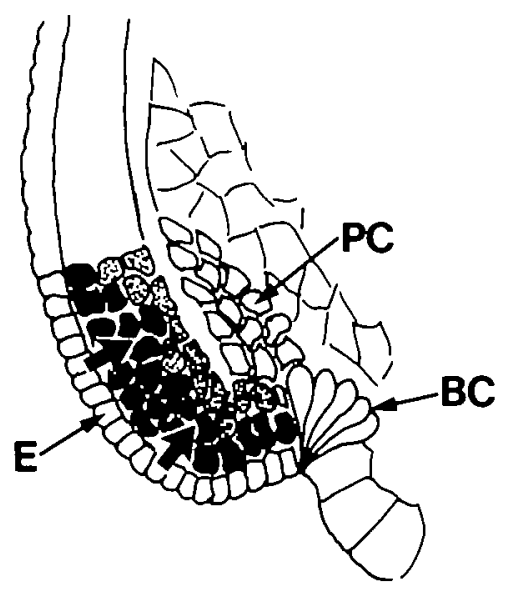

Fig. 11. Our concept of how the dorsal epithelial cells organise medıolateral intercalation is summarized diagrammatically. The dorsal epithelium interacts with the outermost mesodermal cells in the early gastrula (arrows) making it possible for them to do mediolateral cell intercalation at some later time (dark cells). Eventually the remaining, deeper mesodermal cells acquire the same ability (gray cells), either by interacting with the epithelium as they move closer to it by radial intercalation, or by interaction with other deep cells already capable of mediolateral intercalation. The prechordal cells, leading the migration of the mesoderm, are deprived of epithelial influence, having lost contact with their corresponding epithelium, the bottle cells (BC), during the formation of the bottle cells (see Hardin and Keller, 1988) and thus they never express mediolateral cell intercalation behavior. 
Fig. 12. Planar induction of the convergence and extension of the hindbrain-spinal cord is illustrated. The animal ends of explants of IMZ labeled with fluorescein dextran amine (shaded, A) were grafted to the edges of explants of the animal cap (ac), skewered to the

A

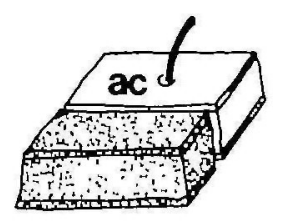

E

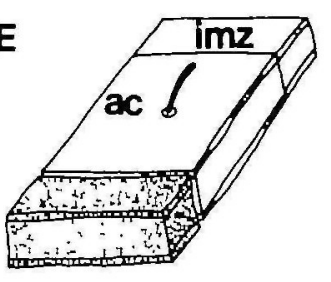
substratum with an eyebrow hair (A). Convergence and extension of the animal cap tissue between the inducing IMZ and the eyebrow hair followed (B,C), whereas this tissue never converges and extends when explanted alone (not shown). Sections show that no labeled inducing tissue had invaded the animal cap region, proving that no vertical inductive interactions between mesoderm (IMZ) and the ectodermal animal cap had occurred (D). When a second IMZ (shaded) was added to the edge of the animal cap, opposite the natıve IMZ $(E)$, a second region of convergence and extension appeared opposite the usual one, but with opposite polarity (F,G). All grafts were taken from the early gastrula stage. Modified from Keller et al., 1992b.
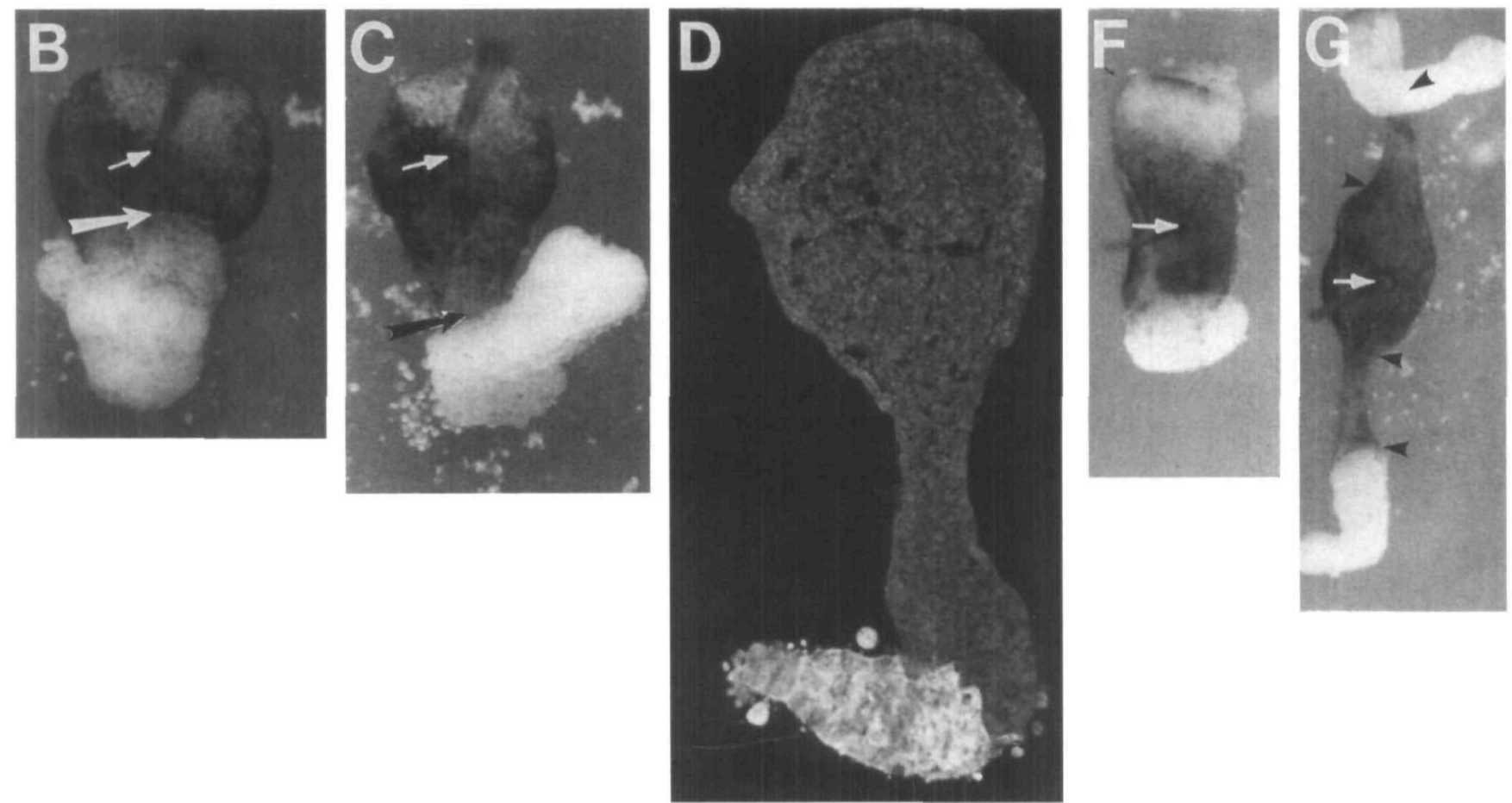

form posterior axial structures with grafts of dorsal epithelium. In both cases, unlabelled host tissues participated in convergence and extension and differentiated into dorsal axial structures as indicated by tissue markers. Grafts of dorsal epithelium to ventral explants results in convergence, extension and differentation of dorsal tissues in the explant (Fig. 10B), whereas control ventral explants do none of these things (Fig. 10C).

We envision the dorsal epithelium interacting with the underlying deep cells early in gastrulation (prior to stage 10.5 ) and either instructing or supporting the commitment of the shallowest deep cells to MIB expression (black shading, Fig. 11) from the outside inward (Fig. 11, arrows). Later, deeper mesodermal cells become committed to MIB expresssion (stippled cells). The prechordal mesoderm (unshaded cells, PC; Fig. 11), which lost contact with the epithelium during bottle cell formation (Hardin and Keller, 1988), are never committed to MIB expression, perhaps because of this loss of contact with the epithelium at the beginning of gastrulation.

\section{Planar induction of neural convergence and extension}

The convergence and extension of the posterior neural plate was not expected in explants (Keller et al., 1985a, b), since no mesoderm underlies this tissue prior to explantation. Thus neural-type convergence and extension could not have occurred by the classical vertical route of neural induction but must involve signals passing within the plane of the dorsal tissue of the embryo (see Keller and Danilchik, 1988) (planar induction see Phillips, 1991, for a review). However, planar induction is difficult to demonstrate for several reasons. Time-lapse tracing of the prospective areas of the neural anlagen show that the entire hindbrain-spinal cord of the neural plate is very broad and very, very short at the onset of gastrulation, and elongates tremendously by radial and mediolateral intercalation during late gastrulation and neurulation (Keller et al., 1992a). Marking experiments show that it is quickly underlain by the involuting mesoderm (Keller et al., 1992a). Moreover, tests of planar induc- 


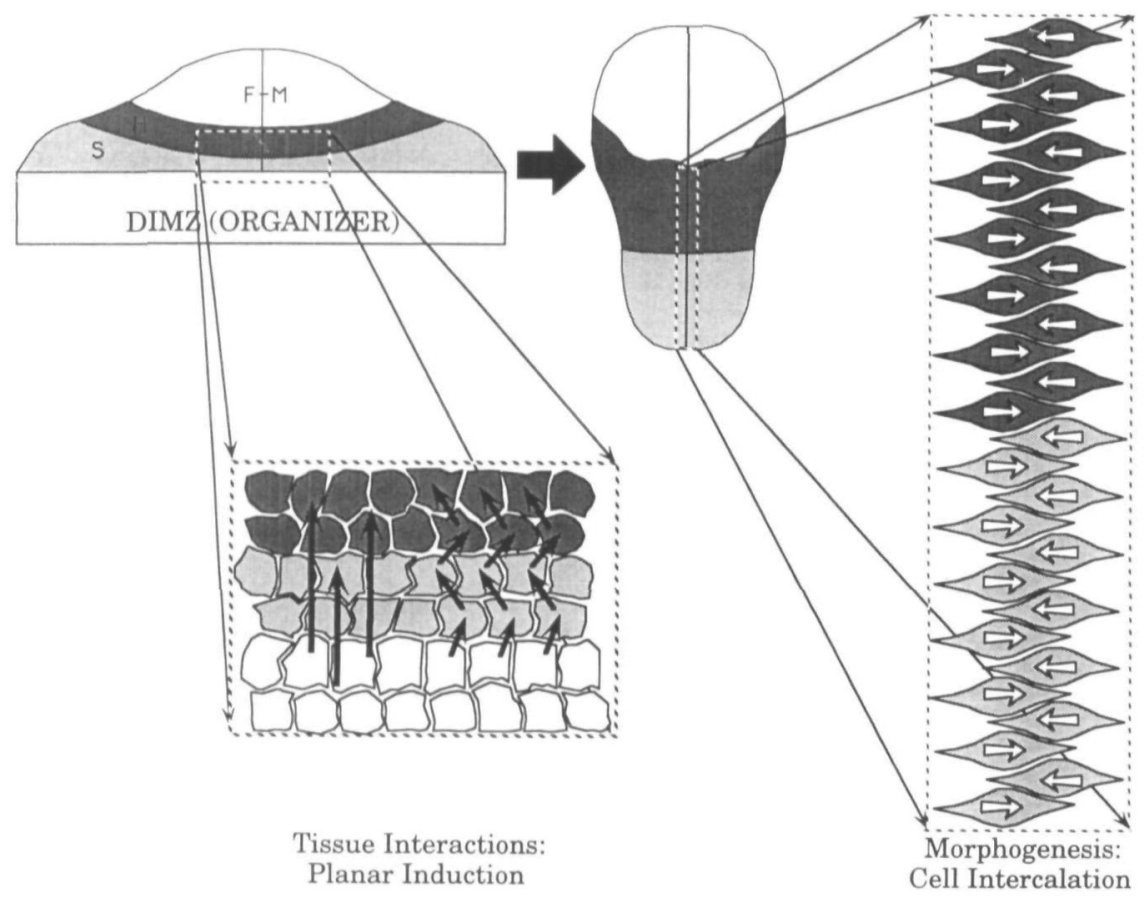

Fig. 13. Schematic diagrams show the significance of planar induction of cell intercalation in neural plate morphogenesis. The background of the figure (top) shows the changes in shape of the the prospective neural plate from the early gastrula through stage 15 , including the forebrain and midbrain (F-M), hindbrain $(\mathrm{H})$ and spinal cord (S) from stage $10+$ to 15 , as if they were flattened out in a plane instead of being wrapped around one side of sphere. Note the convergence and extension of the nervous system, particularly the hindbrain and spinal cord. The foreground (bottom) represents the underlying cellular events in induction and execution of the convergence and extension movements in the hindbrain and spinal cord (Keller et al., 1992a). Planar signals produced by the dorsal involuting marginal zone (DIMZ) act on a few rows of ectodermal cells animal to them in the first part of gastrulation (left). Planar signals could come from the mesoderm directly (long arrows), or relayed through the ectoderm by homeogenetic propagation of the inductive signal (multiple arrows). The morphogenetic response of the ectoderm to planar induction is to undergo radial and mediolateral cell intercalation, to produce a longer, thinner and narrower array of cells (right). Figure and legend from Keller et al., 1992b.

tion depend on removing all leading edge mesoderm from the inner surface of the explant, lest these invasive cells migrate animally in the core of the prospective neural tissues. There they are strung out along the anterior-posterior axis by convergence and extension and thus provide vertical interactions unbeknownst to the investigator (see Fig. 10, Keller, 1991). We solved these problems and demonstrated planar induction of neural convergence and extension by grafting labeled dorsal $\mathrm{IMZ}$ (organiser) to unlabeled animal cap tissue (Fig. 12A). The unlabelled animal cap tissue converges, extends and differentiates as neural tissue (Fig. 12B,C). The labeled IMZ (organiser) tissue retains its planar apposition throughout the experiment, thus precluding vertical interactions (Keller et al., 1992b) (Fig. 12D). Adding another IMZ to the opposite side of the animal cap results in two regions of polarized, neural convergence and extension, one induced by the original IMZ and another induced by the added IMZ (Fig. 12D-G) (Keller et al., 1992b). Cell labeling experiments show that neural convergence and extension take place by the same sequence of radial and mediolateral cell intercalation seen in the mesodermal tissue (Keller et al., 1992a). These two studies (Keller et al. 1992a, b) show how short-range planar signals can induce a large part of the nervous system. Planar signals delivered to the posterior edge of the prospective nervous system in the late blastula and early gastrula act over a short distance to induce cell intercalation. Cell intercalation then greatly elongates and narrows the prospective hindbrain-spinal cord (Fig. 13). The fact that planar signals do not have to act over more than a few cell diameters to induce neural convergence and extension does not preclude action of these or related signals over longer distances, perhaps through the entire brain. Planar signals also induce expression of anterior-posterior markers in their normal order (Doniach et al., this volume). The induced convergence and extension also bears its normal anterior-posterior polarity (Keller et al., 1992b).

\section{Misconceptions}

It is commonly thought that convergence and extension imply that ventral tissue moves dorsally. This does happen but not as part of the initial convergence. Between the early midgastrula (stage 10.5) and the late gastrula (stage 11.5), time-lapse recordings show that convergence brings the dorsal tissue closer to the ventral tissue and extension moves the dorsal blastoporal lip across the yolk plug, the combination of these movements resulting in closure of the blastoporal lips on the ventral aspect of the vegetal endoderm (see Keller and Danilchik, 1988). Convergence of dorsal tissue towards the ventral side is also evident in giant explants of the entire dorsal to ventral extent of the marginal zone (Keller and Danilchik, 1988). After stage 11.5, the blastoporal region is pushed ventrally by the extending notochord (see Figure 1, Keller and Danilchik, 1988) and in explants the mesoderm of the ventral marginal zone that forms the posterior somites is seen streaming around both sides of the blastoporal region and thus 'converging' on a dorsal position next to the notochord (see Wilson et al., 1989; Keller et al., 1989a; Figures 5, 6, Keller et al., 1991b). Thus this late 'convergence', which does actually sweep ventral material dorsally, has a different cellular and mechanical basis than the earlier convergence, which brings all points on the arc closer together, thus pulling the dorsal midline closer to the vegetal endoderm at the lateral ends of the arcs (see Fig. 9, above). 
It is likewise a misconception that mesodermal cells 'migrate' dorsally because more cells find themselves in the dorsal midline than were there originally. The bipolar protrusive activity described above pulls the cells between one another along the full length of the arcs, sweeping from their anchorage in the vegetal endoderm on one side to their corrresponding anchorage on the other side. Cells have never been observed to migrate 'dorsally'. In fact, migration in either direction results when convergence and extension are failing rather than succeeding. When convergence and extension are blocked by mechanical resistence, the cells 'walk' out on one another's surfaces to greater than normal lengths (aspect ratios of 6 or 7) and then they break loose at one end or the other and 'migrate'. This results in mediolateral exchange of places but no effective intercalation (Shih and Keller, 1992b). These behaviors in Xenopus contrast with those in the teleost fish, where convergence movements do involve directed migration (Trinkaus et al., 1992).

\section{Conclusions}

Our recent work has focused on the cellular and mechanical basis of the powerful convergence and extension movements of the notochordal and somitic mesoderm and the hindbrain-spinal cord tissue of Xenopus, and the tissue interactions that regulate these behaviors. The general conclusion of the work described above, and other work as well (see Adams et al., 1990; Koehl et al., 1990; Hardin, 1990), is that relatively simple routines of cell motility and behavior, and rules of contact interaction, acting in the complex geometry and mechanical environment of biological (embryonic) tissues, produce unexpected and extraordinary mechanisms of translating forces developed by individual cells into mass tissue deformations in early embryogensis. These are unexpected and extraordinary only in that they have been largely ignored in modern developmental and cell biology. It is now clear that a large part of the illusive 'mechanism' of morphogenesis lies in the cytomechanics of cell populations, and it is in this arena that the significance and function of individual cells and specific molecules will be defined and given meaning.

We thank Dr Connie Lane, Dr Amy Sater, and Dr Jeremy Green for their insightful comments and suggestions.

\section{References}

Adams, D., Keller, R. and Koehl, M. A. R. (1990). The mechanics of notochord elongation, straightening, and stiffening in the embryo of Xenopus laevis. Development $110,115-130$.

Dale, L. and Slack, J. M. W. (1987). Regional specification within the mesoderm of early embryos of Xenopus laevis Developmem 100, 279 295.

Doniach, T., Phillip, C. and Gerhart, J. (1992) Planar induction of position-specific homeobox genes in the neurectoderm of Xenopus laevis. Science, in press

Doniach, T., Zoltewicz, S. and Gerhart, J. (1992) Induction of anteroposterior neural pattern in Xenopus by planar signals. Development Supplement (this volume).

Gimlich, R. and Cooke, J. (1983). Cell lineage and induction of second nervous systems in amphibian development. Nature 30, 471-473.

Green, J. B. (1992). The role of thresholds and mesoderm inducing factors in axis patterning in Xenopus. In Formatıon and Differentiation of the
Early Embryonic Mesoderm (eds. Lash. J. and Bellaırs, R.) New York. Plenum Press, in press.

Hardin, J. (1990). Context-sensituve cell behaviors during gastrulation. In Control of Morphogenesis by Specific Cell Behavors. (eds. Keller, R. and Fristrom, D.) Semmars in Develop. Bıol. 1, 335-345.

Hardin, J. and Keller, R. (1988). The behavior and function of bottle cells durng gastrulation of Xenopus laevis. Development 103, 211-230.

Jacobson, A. and Gordon, R. (1976). Changes in the shape of the developing vernebrate nervous system analyzed experimentally. mathematically, and by computer simulation. J. Ey) Zool. 197. 191-246.

Keller, R. E. (1975). Vital dye mapping of the gastrula and neurula of Xenopus laevis. I. Prospective areas and morphogenetıc movenents of the superficial layer. Dev. Biol. 42, 222-24l.

Keller, R. E. (1976). Vital dye mapping of the gastrula and neurula of Xenopus laevis. II. Prospectuve areas and morphogenelic movements of the deep layer Dev. Biol. 51, 118-137.

Keller, R. E. (1978). Time-lapse cinemıcrographic analysis of superficial cell behavior dunng and prior to gastrulation in Xenopus laevis. J. Morph. 157, 223-248.

Keller, R. E. (1981). An expenmental analysis of the role of bottle cells and the deep marginal zone in gastrulation of Xenopus laevis $J$ Exp Zool 216, $81-101$.

Keller, R. E. (1984). The cellular basis of gastrulation in Xenopus laevis. active post-involution convergence and extension by mediolateral interdigitation. Am. Zool. 24, 589-603.

Keller, R. E. (1986). The cellular basis of amphibian gastrulation. In Developmental Biology A Comprehensive Symhesis Vol 2. The Cellular Basis of Morphogenesis. (ed. L. Browder) pp. 241-327 New York Plenum Press.

Keller, R. E. (1987) Cell rearrangement in morphogenesss. Zool. Sci. 4. 763-779

Keller, R. (1991) Early embryonic development of Xenopus luevis. In Xenopus laevis: Practical Uses in Cell and Molecular Biology (ed B Kay and B. Peng) Methods in Cell Biology 36. pp.61-I13. San Diego Academic Press.

Keller, R. E., Danilchik, M., Gimlich, R. and Shih, J. (1985a) Convergent extension by cell intercalation during gastrulation of Xenopus laevis In Molecular Determinants of Animal Form (ed. G. M. Edelman), pp. 111-141. San Diego: Academic Press.

Keller, R. E., Danilchik, M., Gimlich, R. and Shih, J. (1985b). The function of convergent extension during gastrulation of Xenopus laevis $J$ Embryol. Exp. Morph. 89 Supplement.185-209.

Keller, R. E. and Trinkaus, J. P. (1987). Rearrangement of enveloping layer cells without disnuption of the epithelial permeability barrier as a factor in Fundulus epiboly. Dev. Brol. 120, 12-24.

Keller, R. E. and Danilchik, M. (1988). Regional expression, pattern and tıming of convergence and extension during gastrulation of Xenopus laevis. Developmem 103,193-210.

Keller, R. E. and Tibbetts, P. (1989). Mediolateral cell Intercalation in the dorsal axıal mesoderm of Xenopus lievis. Dev. Biol. 131, 539-549

Keller, R., Cooper, M. S., Danilchik, M., Tibbetts, P. and Wilson, P. A. (1989a). Cell intercalation during notochord development in Xenopus laevis.J Exp. Zool. 251. 134-154

Keller, R. E., Shih, J. and Wilson, P. A. (1989b). Morphological polarty of intercalatıng deep mesodermal cells in the organizer of Xenopus laevis gastrulae. In Proceedings of the 47/h Annual Meetmg of the Electron Microscopy' Society of America San Francisco: San Francisco Press. p 840.

Keller, R., Shih, J. and Wilson, P. A. (1991a). Cell molilıy, control and function of convergence and extension during gastrulation of Xenopus. In Gastrulanon: Movements, Pattents, and Molecules. (ed. R. Keller. W. Clark and F. Griffin) pp. 101-119. New York: Plenum Press.

Keller, R., Shih, J., Wilson, P. A. and Sater, A. K. (199lb) Pattems of cell motility, cell interactions, and mechanism durıng convergent extension in Xenopus. In Cell-Cell Interactions in Early Developmem. Society for Developmental Biology, 49h Symposumm (ed. G. C. Gerhart) pp. 31-62. New York: Wiley-Liss.

Keller, R. and Shih, J. (1992). Medıolateral cell intercalation of mesodermal cells in the Xenopus laevis gastrula. In Formation and Differentiation of the Earlv Embrionic Mesoderm (ed. J. Lash and R. Bellairs) New York: Plenum Press, in press.

Keller, R., Shih, J. and Sater, A. (1992a). The cellular basis of the convergence and extension of the Xenopus neural plate. Develop. Dynamics 193, 199-217. 
Keller, R. E., Shih, J., Sater, A. K. and Moreno, C. (1992b). Planar induction of convergence and extension of the neural plate by the organizer of Xenopus. Develop. Dynamics 193, 218-234.

Koehl, M. A. R., Adams, D. and Kefler, R. (1990). Mechanical development of the notochord in Xenopus early tail-bud embryos. Biomechanics of Active Movement and Deformation of Cells. NATO ASI Series. Vol. H 42 (ed. N. Akkas) pp. 471-485. Berlin: Springer-Verlag.

Phillips, C. (1991). Effects of the dorsal blastoporal lip and the involuted dorsal mesoderm on neural induction in Xenopus laevis. In Cell-Cell Interactions in Early Development. Society for Developmental Biology, 49th Symposium (ed. G. C. Gerhart) pp. 93-107. New York: WileyLiss.

Schechtman, A. M. (1942). The mechanics of amphibian gastrulation. 1 . Gastrulation-producing interactions between various regions of an anuran egg (Hyla regilia). Univ. Calif. Publ. Zool. 51, 1-39.

Schoenwolf, G. C. and Alvarez, I. C. (1989). Roles of neuroepithelial cell rearrangement and division in shaping the avian neural plate. Development 106, 427-439.

Shih, J. and Keller, R. (1992a). Patterns of cell motility in the organiser and dorsal mesoderm of Xenopus. Development 116, in press.

Shlh, J. and Keller, R. (1992b). Cell motility driving mediolateral intercalation in explants of Xenopus. Development 116, in press.

Shih, J. and Keller, R. (1992c). The epithelium of the dorsal marginal zone of Xenopus has organiser properties. Development 116, in press.
Spemann, H. (1938). Embryonic Development and Induction. New Haven: Yale University Press.

Trinkaus, J. P., Trinkaus, M. and Fink, R. (1992). On the convergent cell movernents of gastrulation in Fundulus. J. Exp. Zool. 261, 40-61.

Vogt, W. (1929). Gestaltungsanalyse am Amphibienkeım mit ontıcher Vitalfarbung. II. Teil. Gastrulation und Mesodermbildung bei Urodelen und Anuren. Wilhelm Roux Arch. EntwMech. Org. 120, 384-706.

Warga, R. and Kimmel, C. (1990). Cell movements during epiboly and gastrulation in zebrafish. Development 108, 569-580.

Weliky, M., Minsuk, S., Oster, G. and Keller, R. (1992). The mechanical basis of cell rearrangement. II. Models for cell behavior driving notochord morphogenesis in Xenopus laevis. Development 113, 12311244.

Wilson, P. (1990). The development of axial mesoderm in Xenopus laevis. $\mathrm{PhD}$. Dissertation, University of California. Berkeley.

Wilson, P. A., Oster, G. and Keller, R. (1989). Cell rearrangement and segmentation in Xenopus: direct observation of cultured explants. Development 105, 155-166.

Wilson, P. A. and Keller, R. E. (1991). Cell rearrangement during gastrulation of Xenopus: direct observation of cultured explants. Development 112, 289-305.

Winklbauer, R. (1990). Mesodermal cell migration during Xenopus gastrulation. I. Interaction of mesodermal cells with fibronectin. Dev. Biol. 142, 155-168. 
